\title{
Performance evaluation of some rain attenuation prediction models at coastal locations at 12 and $40 \mathrm{GHz}$
}

\author{
Abayomi Isiaka O. Yussuff ${ }^{\star}$ and Kabir Momoh \\ Department of Electronic and Computer Engineering, Lagos State University, Lagos, Nigeria. \\ *Corresponding author. Email: abayomi.yussuff@lasu.edu.ng; Tel: +2348033251633.
}

Copyright @ 2021 Yussuff and Momoh. This article remains permanently open access under the terms of the Creative Commons Attribution License 4.0, which permits unrestricted use, distribution, and reproduction in any medium, provided the original work is properly cited.

Received 17th February, 2021; Accepted 9th March, 2021

\begin{abstract}
This work concerns the evaluation of the performances of some selected rain attenuation models at two different locations in Lagos, Nigeria at 12 and $40 \mathrm{GHz}$. Scarcity of rainfall data in the tropical regions resulted in abysmal research efforts into the causes and solutions to satellite signal outages, this was further exacerbated by the convective tropical rain precipitations. The globally adopted ITU-R model, had been declared unsuitable for predicting rain attenuation in the tropics by several researchers in the literature. Two-year (January 2016 to December 2017) local rainfall data were sourced from the Nigerian Meteorological Services (NIMET) for two coastal stations (Ikeja and Oshodi). Rain attenuation exceeded for rain rate at $0.01 \%$ of the time, $A_{0.01}$ was computed after the 1 -hour rain rate integration time which was sourced from NIMET was converted to 1-minute integration time. Attenuation exceeded for other percentages of time were also obtained using statistical interpolation and extrapolation methods. The collected data were tested with ITU-R, SST, SAM, DAH and Silva Mello et al. For Ikeja at $12 \mathrm{GHz}$, the SST was observed to closely match the measurement attenuation at $0.01 \% \leq p \leq 1 \%$ of time exceeded; closely followed by Silver Mello. For Oshodi also at $12 \mathrm{GHz}$, SST intersected with the measured attenuation at $0.01 \% \leq p \leq 0.03 \%$, and $p=0.1 \%$ of time. However, at $40 \mathrm{GHz}$, all the prediction models performed poorly by underestimating the measurement for Ikeja, although SST showed the best effort. The SST model matched the measurement, especially at $p=0.03 \%$ and $p=0.5 \%$ for Oshodi at $40 \mathrm{GHz}$, closely followed by Silva Mello which matched the measurement at $p=0.05 \%$ and $p=0.1 \%$, while ITU-R, SAM and DAH largely underestimated the measurement. The SST was therefore affirmed the overall best performed rain attenuation prediction model for both stations at both frequency bands; closely followed by the Silva Mello. ITU-R, SAM and DAH on the other hand performed poorly. The findings arising from this work could present useful information to satellite equipment designers and manufacturers, while at the same time ensuring that service providers conform to the required service level agreements.
\end{abstract}

Keywords: Attenuation, prediction models, rain rate, slant path, tropics.

\section{INTRODUCTION}

The aggressive demand on satellite communication systems has resulted in increased congestion of the lower frequency bands; hence the need to migrate to higher frequency bands in order to deliver larger channel capacity as observed by Akinyemi (2014). It is therefore pertinent to identify and/or propose effective prediction models to provide design guidelines for communication systems (Mollel and Kisangiri, 2014). Climatic change and increased depletion of the ozone layer have been identified as major threats to stability in the metrological forecast; hence the need for better observation and planning is crucial (Janer, 2016). Microwave links fading could be caused by atmospheric gasses (oxygen and water vapour), as well as absorption and scattering by hydrometeors such as cloud drops, hail and rain (Petr Chýlek and Zhan, 1990; Al-Saegh and Elwi, 2019).

However, attenuation due to rain mostly accounts for the largest protracted fading for radio links operating above 10 $\mathrm{GHz}$, and as such, rain fading can significantly affect the availability of the links (Kalu and Jonathan, 2015). In the 
design of telecommunication systems, the dynamic characteristics of fading due to atmospheric effects are essential in order to optimize system capacity and to achieve quality and reliability of signal reception as observed by Cakaj (2009). Utilization of higher frequency bands such as the $\mathrm{Ku}$ and $\mathrm{Ka}$ band for satellite communications provides a number of key benefits, such as relieving congestion in the lower frequencies (which are also shared with terrestrial links which exploits the larger bandwidths available at higher frequencies) and provision of cheaper implementation of available spectrum as observed by Kumar et al. (2008).

The signal attenuation due to rainfall is caused by the electromagnetic interference of transmitted signal leading to signal degradation which is most severe in tropical and equatorial climates due to convective rainfalls (Abdulrahman et al., 2013). At the Ku-band downlink frequency of $12 \mathrm{GHz}$, the wavelength is $25 \mathrm{~mm}$, which is much greater than the size of a raindrop, except at C-band. At Ka-band, with a downlink frequency of $20 \mathrm{GHz}$, the wavelength is $15 \mathrm{~mm}$ and at V-band, at a downlink frequency of $40 \mathrm{GHz}$, it is only $7.5 \mathrm{~mm}$ (Oluwadare et al., 2012). At these frequencies, the wavelengths and raindrop sizes are comparable and the attenuations were observed to be quite large (Oluwadare et al., 2012). Attenuation is a reduction of signal strength during transmission. Attenuation is represented in decibels $(\mathrm{dB})$, which is ten times the logarithm of the signal power at a particular input divided by the signal power at an output of a specified medium as observed by Omotosho and Oluwafemi (2009). Fading is the term used to explain the fluctuations in a received signal as a result of multipath components (Prasad et al., 2010). As the frequency spectrum becomes increasingly crowded, satellite to earth communication links are shifting to higher frequencies, from C-band to the current Ku-band and Ka-band. Slant path rain attenuation becomes much more severe with increased frequency bands.

This paper presents the performance evaluation of some selected slant path rain attenuation prediction models for the tropics at $\mathrm{Ku}$ and $\mathrm{V}$ frequency bands for two stations in Lagos, Nigeria. Lagos, with geographical coordinates of $6.358 \mathrm{~N}, 3.28 \mathrm{E}$, is a coastal station in the rain forest area of southwestern tropical Nigeria with an altitude of $38 \mathrm{~m}$ above mean sea level (Yussuff and Khamis, 2014). It is bordered on the south by the South Atlantic Ocean, and with a mean annual rainfall of $1521 \mathrm{~mm}$.

The International Telecommunication Union-Radio propagation section (ITU-R) has recommended percentage outages for domestic, commercial and military applications as $0.1,0.01$ and $0.001 \%$ respectively, in order to ensure reliability of satellite equipment that are designed and manufactured by satellite communication engineers. The results of this work would provide useful information required in the design of satellite communication equipment for use in the non-temperate regions of the world.

\section{MATERIALS AND METHODS}

Rain attenuation prediction models for slant path requires certain weather parameters and attenuation statistics for each ground station at the specific frequencies of interest. The synopsis of relevant slant path rain attenuation prediction models and the experimental setup for data collection are presented in this section.

\section{Overview of selected rain models}

Five slant path rain attenuation prediction models were selected and investigated in this work. These are ITU-R Recommendation P. 618-13 (ITU-R), Dissanayake, Allnutt and Haidara (DAH), Simple Attenuation Model (SAM), Synthetic Storm Technique (SST) and Silva Mello et al.

Once the rain attenuation exceeded $\left(A_{0.01}\right)$ for rain rate at $0.01 \%$ of the time is computed, the attenuation exceeded for other percentages of the time is obtained using statistical interpolation and extrapolation methods.

\section{ITU-R Recommendation P. 618-13 Model}

ITU-R Recommendation P. 618-13 (2017) rain attenuation prediction model predicts the long-term statistics of the slant-path rain attenuation at a given location for frequencies up to $55 \mathrm{GHz}$. Rainfall rate at $0.01 \%$ of the time $\left(A_{0.01}\right)$ is the primary input to this model, and the resulting attenuation at this $0.01 \%$ is used for estimating the attenuation exceeded at other percentages of time $\left(A_{\% p}\right)$.

The step-by-step procedures for calculating rain attenuation cumulative distribution function over the satellite link can be found at the ITU website and in the literature. The effective path length $L_{\text {eff }}(\mathrm{km})$ through rain is thereafter obtained by multiplying the horizontally adjusted slant path by the vertical reduction factor. This is expressed as:

$$
L_{\text {eff }}=L_{h 0.01} r_{v 0.01}(\mathrm{~km})
$$

The predicted slant path attenuation exceeded for $0.01 \%$ of an average year is:

$$
A_{0.01}=\gamma_{0.01} L_{e f f}(\mathrm{~dB} / \mathrm{km})
$$

The predicted attenuation exceeded for other percentages $\%$ of an average year may be obtained from the value of $A_{0.01}$ by using the following extrapolation according to ITU-R P. 618-13 (2017) as given in equation (3).

$A_{\% p}=A_{0.01}\left(\frac{p}{0.01}\right)^{-\left[0.655+0.033 \ln p-0.045 \ln A_{0.01}-z \sin \theta(1-p)\right]}(d B)$ 
where $p$ is the percentage probability of interest and $z$ is given by:

For $p \geq 1.0 \%, z=0$

For $p<1.0 \%, z=\left\{\begin{array}{l}0 ; \text { for } / \phi / \geq 36^{0} \\ z=-0.005(/ \phi /-36) \text { for } \theta \geq 25^{0} \text { and } / \phi /<36^{0} \\ z=-0.005(/ \phi-36 /)+1.8-4.25 \sin \theta, \text { for } \theta<25^{0} \text { and } / \phi /<36^{0}\end{array}\right.$

\section{Dissanayake, Allnutt and Haidara Model}

Dissanayake et al. (1997) model is based on log-normal distribution of rain rate and rain attenuation. The model is approximately similar to the ITU-R model because the input to the model is the rain intensity at $0.01 \%$ of the time $\left(A_{0.01}\right)$. The model can be applied to both terrestrial and slant paths within the frequency range of $4-35 \mathrm{GHz}$, at percentage probability range of $0.001-10 \%$. The model can be modelled by the expressions in equation (6), where $A_{p \%}$ and $A_{0.01}$ are attenuations for $p \%$ and $0.01 \%$ of time respectively.

$$
A_{P \%}=A_{0.01}\left(\frac{p}{0.01}\right)^{-\left[0.655+0.033 \ln p-0.045 \ln A_{0.01}-z \sin \theta(1-p)\right]} d B
$$

\section{Simple Attenuation Proposed Model}

The Simple Attenuation Model (Stutzman and Yon, 1986) is a popular slant path attenuation prediction model. It incorporates the individual characteristics of the stratiform and convective types of rainfall and utilizes the point rainfall rate at the ground for the calculation of the attenuation time series, as follows:

$$
\begin{aligned}
& A=\gamma L_{S} ; R_{\% p} \leq 10(\mathrm{~mm} / \mathrm{hr}) \\
& L_{S}=\frac{H_{R}-H_{S}}{\sin \theta}(\mathrm{km})
\end{aligned}
$$

To estimate $\gamma$, for linear and circular polarization, and for all path geometries the ITU-R recommendation P-838-3 (2005) was used to obtain the statistical regression coefficients $k$ and $\alpha$ using the equations (9) and (10) as follows:

$$
\begin{aligned}
& k=\left[k_{H}+k_{V}+\left(k_{H}-k_{V}\right) \cos ^{2} \theta \cos 2 \tau\right] / 2 \\
& \alpha=\left[k_{H} \alpha_{H}+k_{V} \alpha_{V}+\left(k_{H} \alpha_{H}-k_{V} \alpha_{V}\right) \cos ^{2} \theta \cos 2 \tau\right] / 2 k
\end{aligned}
$$

Where $\theta$ is the path elevation angle, and $\tau$ is the polarization tilt angle relative to the horizontal ( $\tau=45$ for circular polarization).

To determine the slant path attenuation, a modified value of effective path length must be used, as follows:

$$
A=\gamma \frac{1-\exp \left[-\gamma b \ln \left(\frac{R_{\% p}}{10}\right)\right] L_{S} \cos \theta}{\gamma b \ln \left(\frac{R_{\% p}}{10}\right) \cos \theta} ; R_{\% p}>10 \mathrm{~mm} / \mathrm{hr}
$$

where the empirical constant $b=1 / 22$;

The following empirical expressions for effective rain height $H_{R}$ were derived from measurement data they obtained:

$$
H_{R}=\left\{\begin{array}{c}
H_{0} ; R \leq 10 \mathrm{~mm} / \mathrm{hr} \\
H_{0}+\log \left(\frac{R}{10}\right) ; R>10 \mathrm{~mm} / \mathrm{hr}
\end{array}\right.
$$

$H_{R}(\mathrm{~km})$ is the rain height, $L_{S}(\mathrm{~km})$ is the slant path up to rain height, $H_{0}(\mathrm{~km})$ is the $0^{\circ} \mathrm{C}$ isotherm height above mean sea level and its value can be obtained from the isotherm chats of ITU-R. P. 839-4 (2013)

\section{Synthetic Storm Technique}

The synthetic storm technique (SST) was first introduced by Drufuca (1973) for terrestrial radio link. The SST input data was obtained from a rain gauge record by converting the raw data of rainfall rate versus time into a function of distance by employing a storm translation velocity to transform time to distance. The synthesized storms express rainfall rate, $R$ as a function of distance, $x$ by approximating the statistical properties of a large number of synthetic storms with the corresponding statistical properties of real storms using a statistical approach known as the "Taylor's hypothesis". The rainfall rate was the converted to specific attenuation, $y$ using Equation (2). The attenuation over a distance $L$ was then calculated by Integrating $\gamma(x)$ over an interval of length $L$ using: 


$$
A\left(x_{0}, L\right)=\int_{x_{0}}^{x_{0}+L} \gamma(x) d x(d B)
$$

Attenuation was calculated as a function of time for this storm from Equation (13) with $L$ set at 5 miles and $x_{0}$ changing at a rate of 14 miles/hr; with values of $k$ and $\alpha$ selected at $11.2 \mathrm{GHz}$.

SST is a model aimed at converting time into distance and rain rate time series into rain attenuation time series, and a useful tool to obtain rain attenuation series from rain rate series for any satellite radio link with elevation angle above $10^{\circ}$, at any frequency and at polarization from any site, as long as the spatial-temporal field isotropy holds. The required input into the model includes advection velocity of rain cells, the slant path length and the rain rate time series of the location of interest.

The SST slant path vertical structure is modeled into tropospheric two layers, A and B. Layer A represents the rain layer where precipitation occurs while layer $B$ is the melting layer where ice transforms into water as it begins to melt; dramatically changing the physical, electrical, dynamic and morphological properties of the hydrometeors. Layer $A$ is characterized by homogenous rain precipitation of rate $R_{A}$ while layer $\mathrm{B}$ is representative of ice with apparent rain rate $R_{B}$. The relationship between $R_{A}$ and $R_{B}$ is:

$$
R_{B}=3.134 R_{A}(\mathrm{~mm} / \mathrm{hr})
$$

The slant path rain attenuation from the specific attenuation at a point is given as:

$$
A=\int_{0}^{L_{A}} K_{A} R^{\alpha_{A}}\left(x_{0}+\Delta x_{0}, \zeta\right) \delta \zeta+K_{B}(3.134)^{\alpha_{B}} \int_{L_{A}}^{L_{B}} R^{\alpha_{B}}\left(x_{0}, \zeta\right) \delta \zeta(d B)
$$

where $\zeta$ is the distance measured along the satellite slant path, $k$ and $\alpha$ are correlation coefficients dependent on satellite signal frequency, polarization, elevation and rain drop size distribution. These can be obtained from ITU-R P.838-3 (2005) for water at $20^{\circ} \mathrm{C}$ and Parson's law drop size distribution for $0{ }^{\circ} C$. According to Magorri (1981), the radio path lengths $L_{A}$ and $L_{B}$ are defined as:

$$
\begin{aligned}
& L_{A}=\left(H_{A}-H_{S}\right) / \sin \vartheta \\
& L_{B}=\left(H_{B}-H_{S}\right) / \sin \vartheta
\end{aligned}
$$

However, Matricciani (1996) discovered the probability distribution function generated by SST can reliably be modeled by the relationship in equation (17).

$$
A=\left[C_{0} K_{A} R^{\alpha_{A}}+\left(1-C_{0}\right) K_{B}(3.134 R)^{\alpha_{B}}\right] L^{m}(d B)
$$

$L(\mathrm{~km})$ is the average long term slant path in the precipitation (and not an equivalent path length because it does not depend on radio electrical parameters) as given by ITU-R. P.839-4 (2013), and it is defined according to Matricciani (2006) and Matricciani (2008) by the following relationship:

$$
L=L_{A}+L_{B}
$$

The value of the parameter $m$ is computed from

$$
m=\Delta A / A / \Delta L / L
$$

The integration constant

$C_{0}=L_{A} / L=\frac{0.4}{H_{B}-H_{S}}$

where $H_{B}$ is the height of the top limit of the melting layer and $0.4 \mathrm{~km}$ is assumed melting layer thickness.

\section{Silva Mello and Pontes}

This modified model eliminates some of the shortcomings encountered in the ITU-R P. 618-13 model. It however retains the general expression for effective path length by adopting the full rainfall rate distribution over the link as input for the prediction of the rain attenuation. Here, the effective path length is extended for the slant path situation by considering the rain height as a function of $0{ }^{\circ} \mathrm{C}$ (obtained from ITU-R P.839-3 recommendation global map). For a slant path with an elevation angle $\theta$, the effective path length will be given. For the slant path case, $L_{S}$ can be obtained from equation (8). The general expression for rain attenuation prediction is given by Mello and Pontes (2012) as:

$$
\text { Ap }=\mathrm{k}\left(1.736 R^{0.753+\frac{0.197}{l s \cos \theta}} \cos \theta+\frac{203.6}{l s^{2.455}} R^{0.354+\frac{0.088}{l s \cos \theta}} \sin \theta\right)^{\alpha} \frac{1}{1+} \frac{L S \cos \theta}{119 R^{-0.244}}
$$




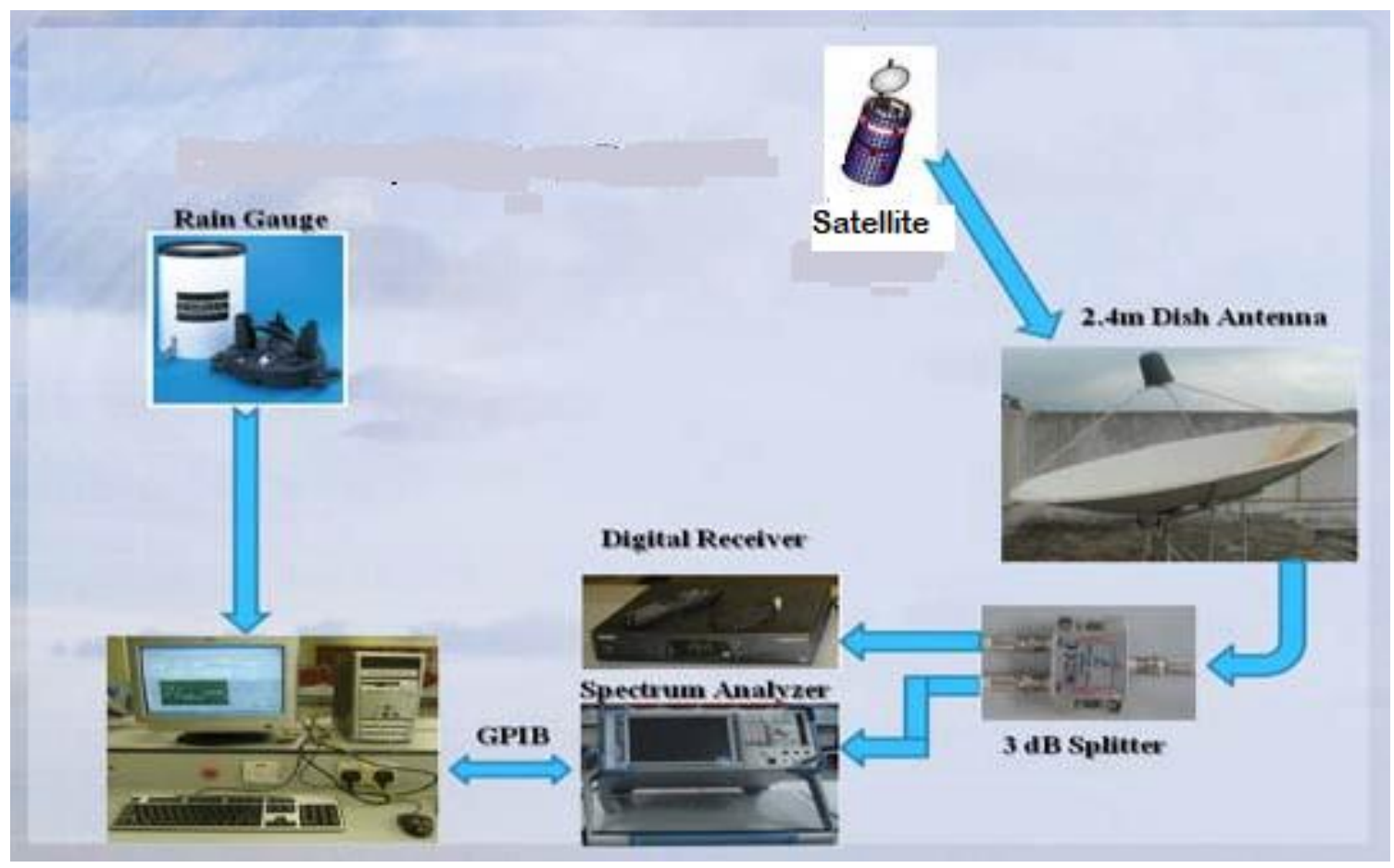

Figure 1. Experimental setup for rain rate and beacon signal level.

Table 1. Monthly rainfall for 2016 and 2017 (NIMET, 2018).

\begin{tabular}{cccccccccccccc}
\hline Year & Jan & Feb. & Mar & Apr & May & Jun & Jul & Aug & Sep & Oct & Nov & Dec & Total \\
\hline 2016 & 0.0 & 0.0 & 71.0 & 91.3 & 234.8 & 124.9 & 115.6 & 81.5 & 301.1 & 343.9 & 48.5 & 14.2 & 1426.8 \\
2017 & 1.4 & 25.6 & 90.8 & 91.2 & 231.8 & 370.3 & 296.1 & 93.3 & 176.9 & 209.1 & 0.0 & 29.0 & 1615.5 \\
\hline
\end{tabular}

\section{Rain data and equipment set up}

Two years (January 2016 to December 2017) data was obtained from the Nigerian Metrological Agency (NIMET) for both Ikeja and Oshodi stations. Ikeja (6.358N,3.28E) and Oshodi $(6.27 \mathrm{~N}, 3.25 \mathrm{E})$ are the two NIMET measurement stations located in Lagos, Nigeria. The measurement setup at NIMET comprises indoor and the outdoor units. The indoor unit consists of spectrum analyzer, field strength meter and a satellite tracker (digital receiver). The obtained parameters, such as signal strength during clear air and other precipitations can then be recorded and analyzed. Rain rate data is collected from the weather station located at the premises of NIMET, situated in the same geographical location where beacon signal from satellite at a downlink frequency of $12.437 \mathrm{GHz}$ and recorded. The outdoor equipment is a dish antenna with low noise block converter (LNBC), which was passed through a $3 \mathrm{~dB}$ splitter and fed into a digital receiver and a spectrum analyzer, as shown in Figure 1. The spectrum analyzer was set to $10.982 \mathrm{GHz}$ and the video filter output of the spectrum analyzer was recorded and stored in a computer at a sampling rate of $1.0 \mathrm{~Hz}$, using a data logger.
A buck-type rain gauge rain gauge was installed at the measurement site to record the rain rate. This tipping bucket rain gauge has a sensitivity of $0.5 \mathrm{~mm} / \mathrm{min}$, with operating temperature range of -10 to $50{ }^{\circ} \mathrm{C}$. It has a tipping accuracy of $100 \%$. Scintillations are removed with a low-pass filter by passing low-frequency signals while attenuating signals with frequencies above the cut-off frequency.

NIMET controls and stores measured hydrometeorological data from its various forecast stations, spread across Nigeria. The automation of the NIMET weather station is achieved by interconnecting some of the sensors of the digital weather equipment to a central processor. The data is stored in a logger or transmitted by cable or radio signal to one or more remote locations as it is observed in the operation room of Nigerian metrological Agency. The proportion of rainfall $(\mathrm{mm})$ is quite good in the year compared to previous years as presented in Table 1.

Chebil and Rahman's rain rate conversion method (Chebil and Rahman, 1999a; Chebil and Rahman, 1999b) was used to convert the hourly data into its equivalent oneminute rain rates integration time, as follows: 
$C F 60=\frac{R 1(p)}{R 60(p)}=a p^{b}$

$C F 60=a p^{b}+c * \exp (d p)$

Where $a, b, c$ and $d$ are regression coefficients derived from Segal (1986) using Gauss-Newton technique for the evaluation. From equation (23), the following relationship was derived:

$C F 60=0.772 * p^{-0.041}+1.141 * \exp (-2.57 * p)$

where $C F 60$ is the rain rate conversion factor, defined as the ratio of rain rates $R 1(p)$ and $R 60(p)$ for a given percentage of time $p$ with an integration time of $1 \mathrm{~min}$ and $60 \mathrm{~min}$, respectively. Although this model is applicable for the range $0.001 \% \leq p \leq 1.0 \% 0.001 \%$, nonetheless, if $R 60(p)$ is known, then $R 1(p)$ can be derived as:

$R 1(p)=R 60(p) * C F 60$

\section{RESULTS AND DISCUSSION}

Figure $2 \mathrm{a}$ presents the slant path attenuation with respect to rain rates at $12 \mathrm{GHz}$ for Ikeja, while Figure $2 \mathrm{~b}$ shows the slant path attenuation with respect to percentages of time exceeded for the same location at $12 \mathrm{GHz}$. At $0.01 \% \leq p \leq$ $1 \%$ percentage of time, the SST closely matched the measurement values while the ITU-R, Silver Mello, SAM and DAH models underestimated the measurements for the same percentages of time exceedance.

Figures $3 a$ and Figure $3 b$ illustrates the slant path attenuation with respect to rain rates and slant path attenuation with respect to percentages of time exceeded, respectively for Oshodi at $12 \mathrm{GHz}$. It was observed that he SST closely matched the measured attenuation values, especially at $0.01 \% \leq p \leq 0.1 \%$ of the time exceeded (Table 2); thus, exhibiting the best performance. Silva Mello model closely followed by showing good performances all through $0.001 \% \leq p \leq 1 \%$. Again, the ITU-R, SAM and $\mathrm{DAH}$ rain models underestimated the measurements.

However, for Ikeja at $40 \mathrm{GHz}$ (Figures $4 \mathrm{a}$ and b), all the prediction models investigated performed poorly by underestimating the measurement, even though the SST showed the best effort. Also, at the same $40 \mathrm{GHz}$, at the Oshodi station (Figures $5 \mathrm{a}$ and $\mathrm{b}$ ), indicates that the SST model matched the measurement, especially at $p=0.03 \%$ and $p=0.5 \%$. The Silva Mello model followed closely, matching the measurement value at $p=0.05 \%$ and $p=$ $0.1 \%$. Again, ITU-R, SAM and DAH largely underestimated the measurement.

Variation in slant path attenuation with changing frequencies for Ikeja and Oshodi stations are shown in Figures $6 a$ and $b$ respectively. It is clearly seen that slant peth attenuation increases with increasing frequency of signal transmission.

The relative underestimation of the ITU-R model was

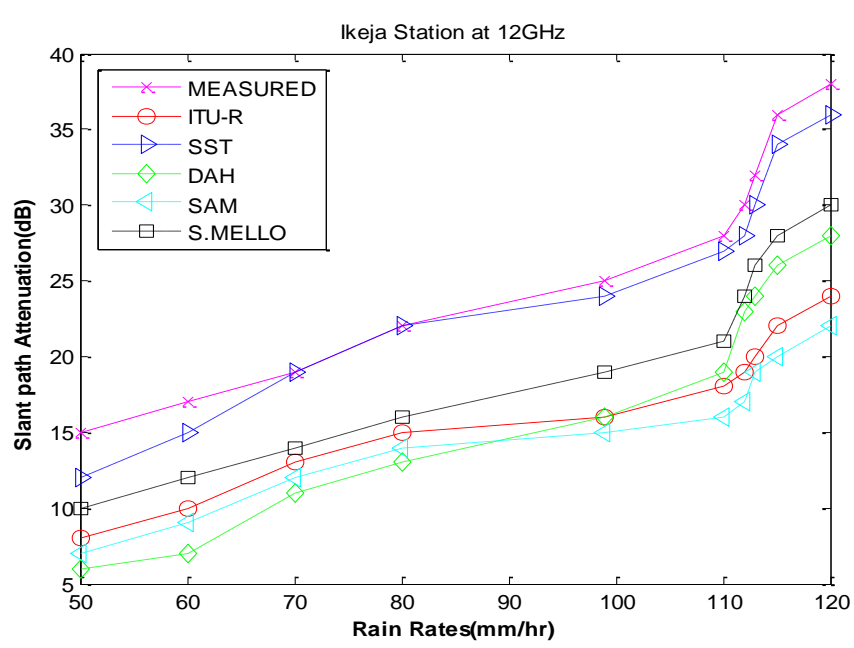

Figure 2a. Slant path attenuation with respect to rain rates at $12 \mathrm{GHz}$ for Ikeja.

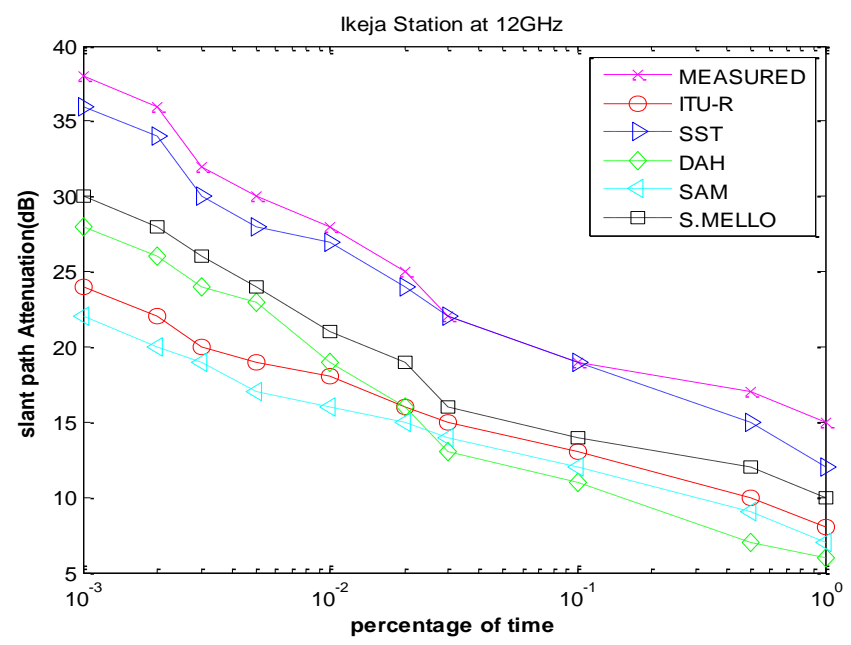

Figure $\mathbf{2 b}$. Slant path attenuation with respect to percentage of time at $12 \mathrm{GHz}$ for Ikeja.

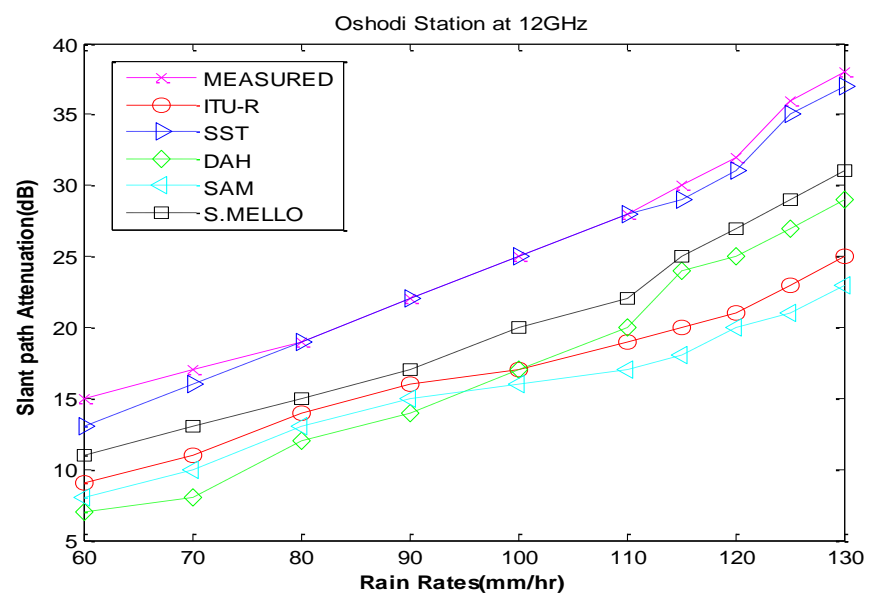

Figure 3a. Slant path attenuation with respect to rain rates at $12 \mathrm{GHz}$ for Oshodi. 


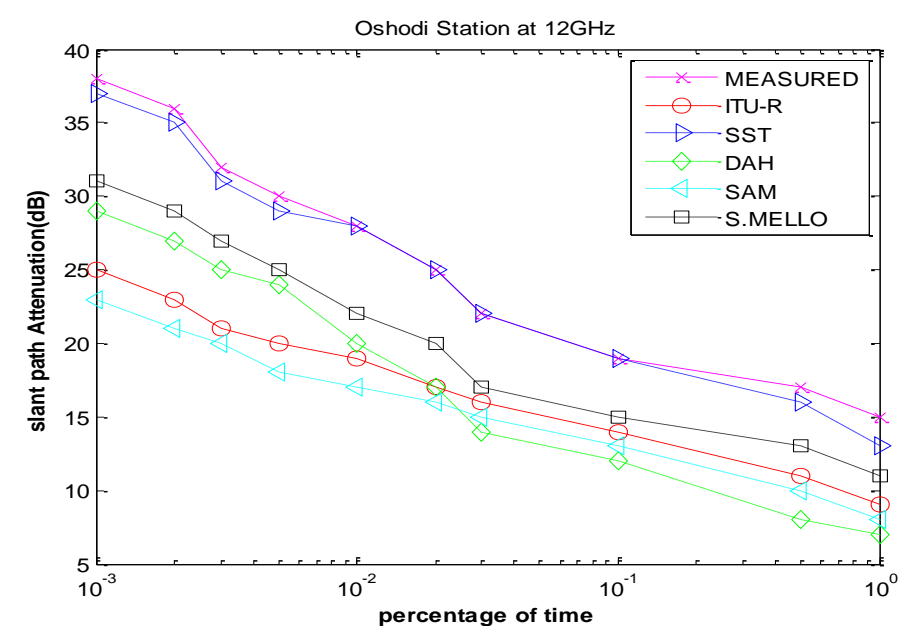

Figure 3 b. Slant path attenuation with respect to percentage of time at $12 \mathrm{GHz}$ for Oshodi.

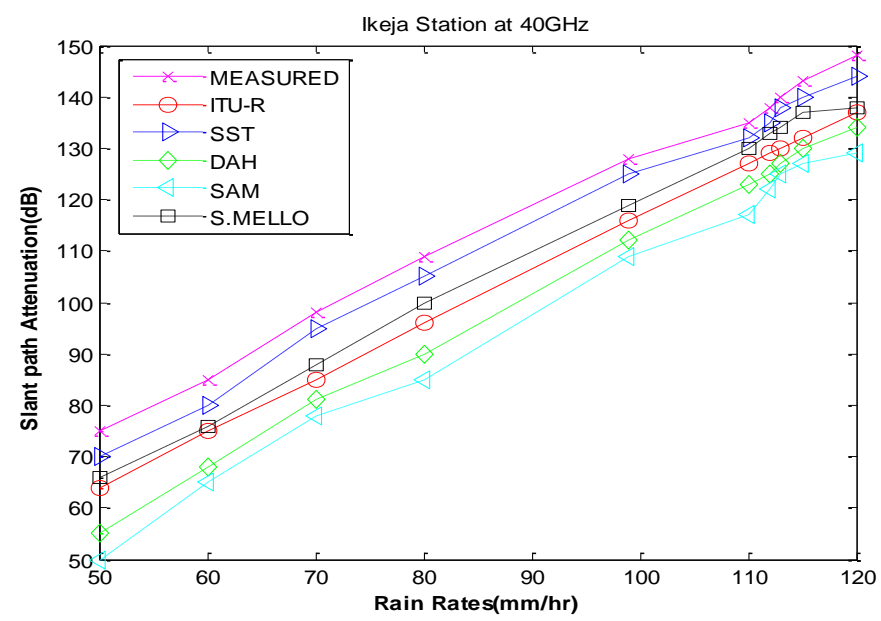

Figure 4a. Slant path attenuation with respect to rain rates at $40 \mathrm{GHz}$ for lkeja.

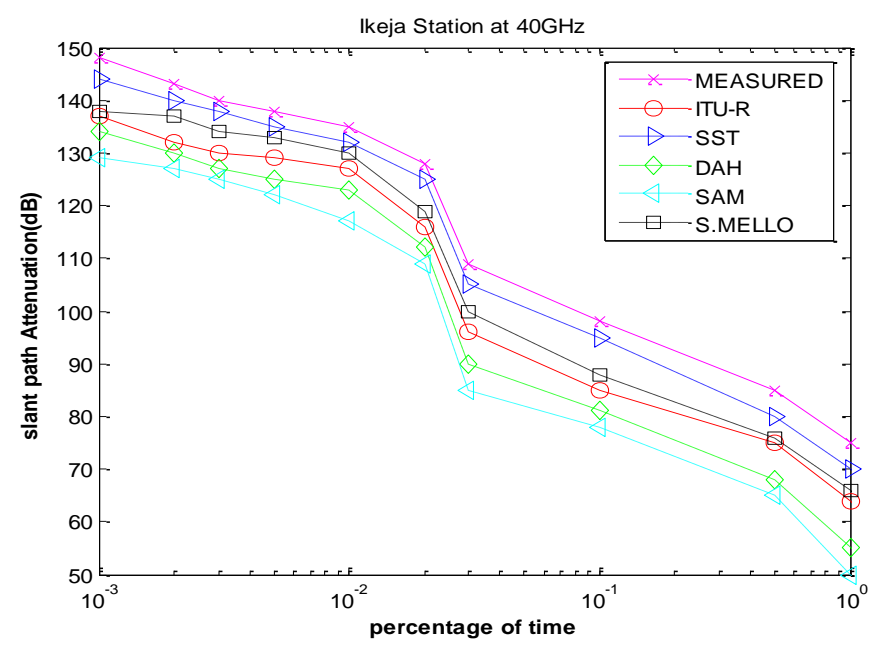

Figure 4b. Slant path attenuation with respect to percentage of time at $40 \mathrm{GHz}$ for Ikeja.

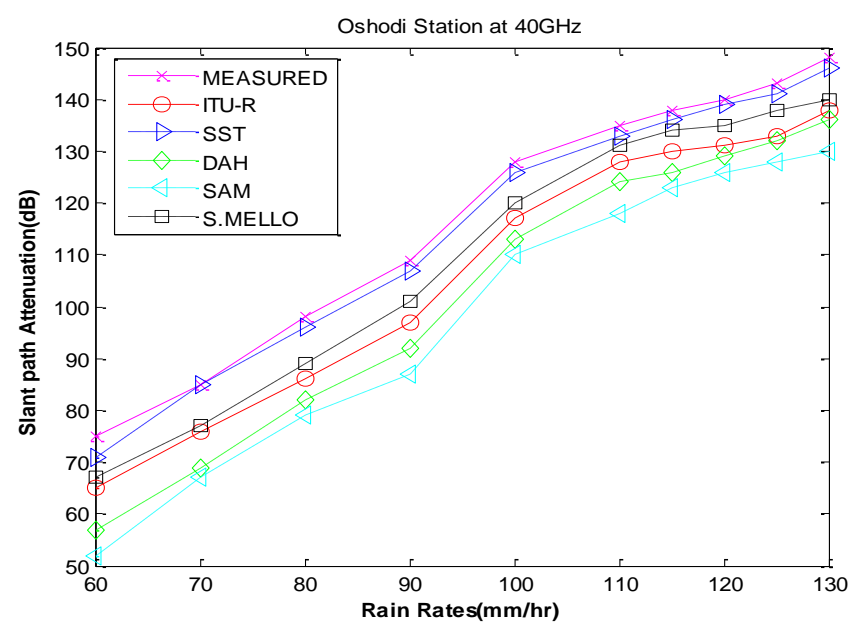

Figure 5a. Slant path attenuation with respect to rain rates at $40 \mathrm{GHz}$ for Oshodi.

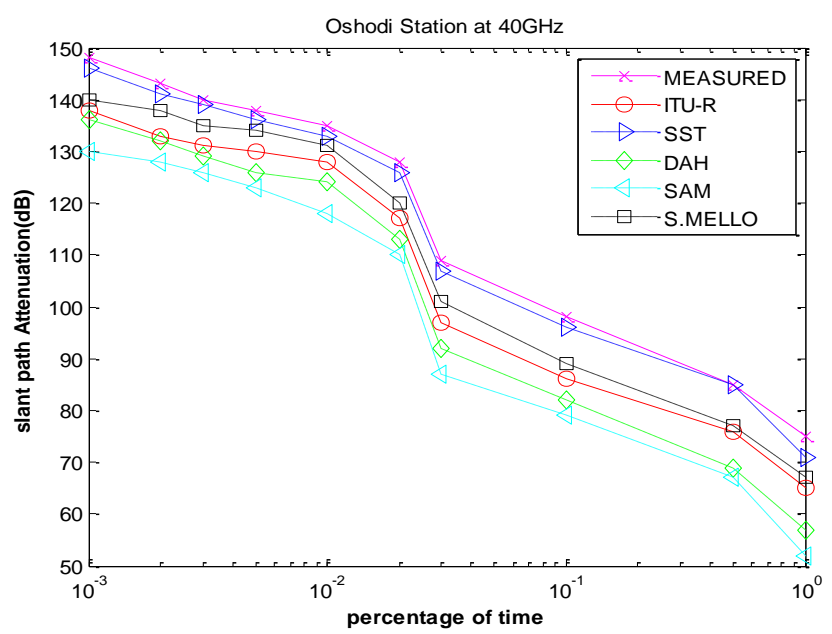

Figure 5b. Slant path attenuation with respect to percentage of time at $40 \mathrm{GHz}$ for Oshodi.

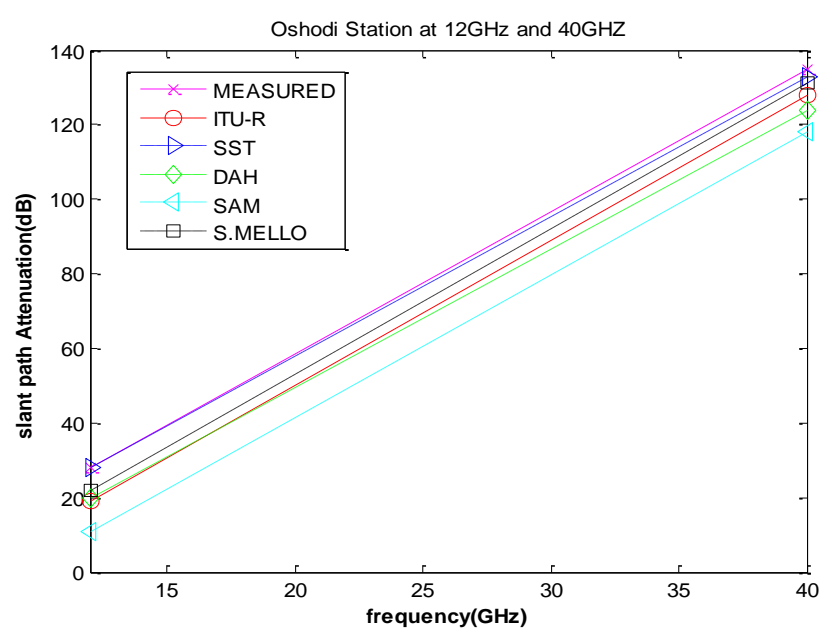

Figure 6a. Slant path attenuation variation with changing frequency for Ikeja station. 


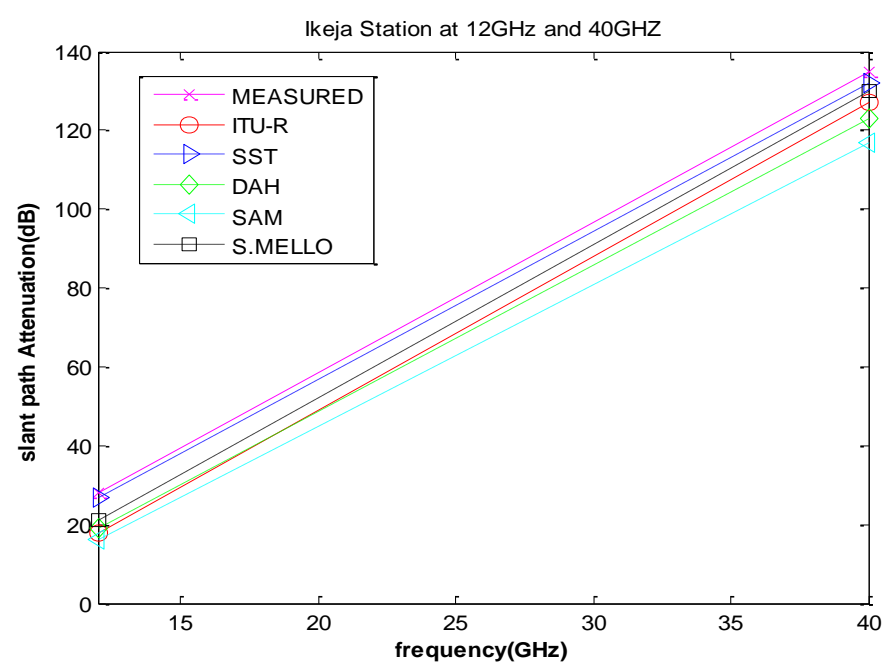

Figure 6b. Slant path attenuation variation with changing frequency for Oshodi station.

corroborated by Singh et al. (2007). The slant path rain attenuation predicted was higher for Oshodi when compared to Ikeja because rain rate recorded for Oshodi is slightly higher. This is because rainfall rate distribution is directly proportional to the slant path rain attenuation (Singh et al., 2007), causing path loss, which depletes spectral efficiency and system performance within the coverage area. The statistical error analysis (RMS (root mean square), standard deviation and mean values) for the prediction models under investigation at both Ikeja and Oshodi stations are given in Table 2 (see Appendix). According to the ITU-R, P. 311-17 (2017), the best prediction method is that with smallest values of the statistical parameters; hence, the SST prediction model presented the overall best performances for both $12 \mathrm{GHz}$ ) and $40 \mathrm{GHz}$ frequency bands. This was closely followed by the Silva Mello model.

\section{Conclusion}

This research work presented the performance evaluation of some slant path rain attenuation prediction models at Ka and Ku frequency bands for two stations in Lagos, Nigeria. Overall, the SST prediction model was the most reliable at both frequency bands for both Ikeja and Oshodi stations by closely matching the measured attenuation values. It was closely followed the Silva Mello, while the ITU-R largely underestimated the measurement for most percentage time exceeded. Again, this is another confirmation of the unreliability of the ITU-R, P. 618-13. (2017) as a globally recommended earth-to-space rain attenuation prediction model, especially for tropical and equatorial regions. This might be due to the assumption of homogeneous rain rate along the slant path used in the formulation of the model. Also, SAM and DAH models performed poorly all through the time exceeded $(0.001 \% \leq$ $p \leq 1 \%)$.

Furthermore, this work adopted the semi-empirical approach, which saves cost and time. More importantly, semi-empirical prediction models are portable in the sense that they can quite easily be extrapolated to other sites and with relatively good degree of accuracy; hence, making it possible to estimate the slant path attenuation exceeded for any location of interest and for all percentages of time.

Consequently, there is need to update the ITU-R P. 61813. (2017) model with a more suitable one for the tropical regions to improve the accuracy and reliability of slant path rain attenuation predictions for use by satellite communication equipment designers and engineers for domestic $(p=0.1 \%)$, commercial $(p=0.01 \%)$, and military $(p=0.001 \%)$ applications. More so, as there is currently paucity of rain database for use in the tropical regions. However, there is need to consolidate on this work by extending the acquired rain data to ten years to better ascertain the suitability or otherwise of these selected rain prediction models for use in the tropical region.

\section{CONFLICT OF INTEREST}

The authors declare that they have no conflict of interest.

\section{ACKNOWLEDGMENT}

The authors would like to thank the Nigerian Metrological Agency (NIMET) for providing the rain data for this work.

\section{REFERENCES}

Abdulrahman, A., Rahman, T. A., Islam, M. R., Olufeagba, B. J., Yussuff, A., \& Khamis, N. H. (2013). An improved slant path attenuation prediction method in tropical climates. Radioengineering, 22(4), 1082-1089.

Akinyemi, A. G. (2014). Estimation of rain attenuation at C, Ku, $\mathrm{Ka}$ and $\mathrm{V}$-bands for satellite links in nigeria (Doctoral dissertation, Redeemer University). Pp. 1-109.

Al-Saegh, A. M., \& Elwi, T. A. (2019). Direct extraction of raininduced impairments on satellite communication channel in subtropical climate at $\mathrm{K}$ and $\mathrm{Ka}$ bands. Telecommunication Systems, 74, 15-25.

Cakaj, S. (2009). Rain attenuation impact on performance of satellite ground stations for low earth orbiting (LEO) satellites in Europe. International Journals of Communications, Network and System Sciences, 9, 480-485.

Chebil, J., \& Rahman, T. A. (1999a). Rain rate statistical conversion for the prediction of rain attenuation in Malaysia. Electronics Letters, 35(12), 1019-1021.

Chebil, J., \& Rahman, T. A. (1999b). Development of 1 min rain rate contour maps for microwave applications in Malaysian Peninsula. Electronics Letters, 35(20), 1772-1774.

Chýlek, P., \& Zhan, J. (1990). Absorption and scattering of light by small particles: The interference structure. Applied optics, 29(28), 3984-3984. 
Dissanayake, A., Allnutt, J., \& Haidara, F. (1997). A prediction model that combines rain attenuation and other propagation impairments along earth-satellite paths. IEEE Transactions on antennas and propagation, 45(10), 1546-1558.

Drufuca, G. (1973). Rain Attenuation Studies. United States Air Force: Canada: 1-105.

ITU-R, P. 311-17 (2017). Acquisition, presentation and analysis of data in studies of tropospheric propagation. International Telecommunication Union.

ITU-R, P. 618-13. (2017). Propagation data and prediction methods required for the design of Earth-space telecommunication systems. International Telecommunication Union.

ITU-R, P. 839-4 (2013). Rain height model for prediction methods. International Telecommunication Union.

ITU-R. P.838-3. (2005). Specific attenuation model for rain for use in prediction methods. International Telecommunication Union.

Janer Cifre, S. (2016). Rainfall estimation from telecommunication network (Bachelor's thesis, Universitat Politècnica de Catalunya). Pp. 1-64.

Kalu, C., Ozuomba, S., \& Jonathan, O. A. (2015). Rain rate trendline estimation models and web application for the global ITU rain zones. European Journal of Engineering and Technology, 3(9), 14-29.

Kumar, S., Bhaskara, V., \& Narayana Rao, D. (2008). Prediction of $\mathrm{Ku}$ band rain attenuation using experimental data and simulations for Hassan, India. International Journal of Computer Science \& Network Security, 8, 10-15.

Magorri, D. (1981). Computed transmission through rain in the 1$400 \mathrm{GHz}$ frequency range for spherical and elliptical drops and any polarization. Alta Frequenza, 50, 262-273.

Mandeep, J. S., \& Tanaka, K. (2007). Effect of atmospheric parameters on satellite link. International Journal of Infrared and Millimeter Waves, 28(10), 789-795.

Matricciani, E. (1996). Physical-mathematical model of the dynamics of rain attenuation based on rain rate time series and a two-layer vertical structure of precipitation. Radio Science, 31(02), 281-295.

Matricciani, E. (2006, November). A fundamental differential equation that links rain attenuation to the rain rate measured at one point, and its applications in slant paths. In: 2006 First European Conference on Antennas and Propagation. Pp. 1-6.

Matricciani, E. (2008). Global formulation of the Synthetic Storm Technique to calculate rain attenuation only from rain rate probability distributions. In: 2008 IEEE Antennas and Propagation Society International Symposium. Pp. 1-4.
Mello, L., \& Pontes, M. S. (2012). Unified method for the prediction of rain attenuation in satellite and terrestrial links. Journal of Microwaves, Optoelectronics and Electromagnetic Applications, 11(1), 1-14.

Mitić, D., Lebl, A., Trenkić, B., \& Markov, Ž. (2015). An overview and analysis of BER for three diversity techniques in wireless communication systems. Yugoslav Journal of Operations Research, 25(2), 251-269.

Mollel, M. S., \& Kisangiri, M. (2014, July). An overview of various propagation model for mobile communication. In Proceedings of the 2nd Pan African International Conference on Science, Computing and Telecommunications (PACT 2014) (pp. 148153). IEEE.

NIMET (2018). Agrometeorological Bulletin No.8, Dekad 2, March $(11-20) 2018$ ISSN: 2315-9790, Nigerian meteorological agency, 8, 10-12.

Oluwadare, E. J., Tomiwa, A. C., \& Ajewole, M. O. (2012). Investigation of Radiowave propagtion impairment at super high frequency due to Rain in Akure. American International Journal of Contemporary Research, 2(10), 122-137.

Omotosho, T. V., \& Oluwafemi, C. O. (2009). Impairment of radio wave signal by rainfall on fixed satellite service on earth-space path at 37 stations in Nigeria. Journal of Atmospheric and Solar-Terrestrial Physics, 71(8-9), 830-840.

Prasad, M. S. G., Siddaiah, P., Reddy, L. P., \& Lekha, K. (2010). Analysis of fast fading in wireless communication channels. Intl Journal of Systems and Technologies, 3(1), 139-145.

Segal, B. (1986). The influence of raingage integration time, on measured rainfall-intensity distribution functions. Journal of Atmospheric and Oceanic Technology, 3(4), 662-671.

Singh, M. S. J., Hassan, S. S., \& Ain, M. F. (2007). Rainfall attenuation and rainfall rate measurements in Malaysia comparison with prediction models. American Journal of Applied Sciences, 4(1),5-7.

Stutzman, W. L., \& Yon, K. M. (1986). A simple rain attenuation model for earth-space radio links operating at 10-35 GHz. Radio science, 21(1), 65-72.

Yussuff, A. I. O. (2016). Analysis of Selected Earth-Space Rain Attenuation Models for a Tropical Station. Indonesian Journal of Electrical Engineering and Computer Science, 3(2), 383-391.

Yussuff, A. I., \& Khamis, N. H. (2012). Rain attenuation modelling and mitigation in the tropics: brief review. International Journal of Electrical and Computer Engineering, 2(6), 748-757.

Yussuff, A. I., \& Khamis, N. H. H. (2014). Rain attenuation prediction model for lagos at millimeter wave bands. Journal of Atmospheric and Oceanic Technology, 31(3), 639-646. 


\section{APPENDIX}

Table 2. Mean, standard deviation, and RMS error comparisons.

\begin{tabular}{|c|c|c|c|c|c|c|c|c|c|c|}
\hline \multirow{2}{*}{$\mathrm{P} / \mathrm{P}$ models } & \multicolumn{10}{|c|}{ Time Percentage ( $\mathrm{p} \%)$} \\
\hline & 0.001 & 0.002 & 0.003 & 0.005 & 0.01 & 0.02 & 0.03 & 0.1 & 0.5 & 1.0 \\
\hline & \multicolumn{10}{|c|}{ IKEJA - 12GHz } \\
\hline \multicolumn{11}{|l|}{ MEAN } \\
\hline ITU-R & -0.0368 & -0.0389 & -0.0375 & -0.0367 & -0.0357 & -0.0360 & -0.0318 & -0.0316 & -0.0412 & -0.0467 \\
\hline SST & -0.0053 & -0.0056 & -0.0063 & -0.0067 & -0.0036 & -0.0040 & 0 & 0 & -0.0118 & -0.0200 \\
\hline $\mathrm{DAH}$ & -0.0263 & -0.0278 & -0.0250 & -0.0233 & -0.0321 & -0.0360 & -0.0409 & -0.0421 & -0.0588 & -0.0600 \\
\hline SAM & -0.0421 & -0.0444 & -0.0406 & -0.0433 & -0.0429 & -0.0400 & -0.0364 & -0.0368 & -0.0471 & -0.0533 \\
\hline S.MELLO & -0.0211 & -0.0222 & -0.0187 & -0.0200 & -0.0250 & -0.0240 & -0.0273 & -0.0263 & -0.0294 & -0.0333 \\
\hline \multicolumn{11}{|l|}{ STD.DEV } \\
\hline ITU-R & 0.0071 & 0.0102 & 0.0013 & 0.0080 & 0.0115 & 0.0106 & 0.0199 & 0.0203 & 0.0170 & 0.0277 \\
\hline SST & 0.0066 & 0.0064 & 0.0057 & 0.0052 & 0.0076 & 0.0074 & 0.0084 & 0.0084 & 0.0082 & 0.0181 \\
\hline $\mathrm{DAH}$ & 0.4193 & 0.4192 & 0.4194 & 0.4195 & 0.4189 & 0.4186 & 0.4181 & 0.4180 & 0.4160 & 0.4158 \\
\hline SAM & 0.4275 & 0.4272 & 0.4276 & 0.4274 & 0.4274 & 0.4277 & 0.4280 & 0.4280 & 0.4270 & 0.4262 \\
\hline S.MELLO & 0.2501 & 0.2500 & 0.2503 & 0.2502 & 0.2498 & 0.2499 & 0.2495 & 0.2496 & 0.2493 & 0.2488 \\
\hline \multicolumn{11}{|l|}{ RMS } \\
\hline ITU-R & 0.0361 & 0.0402 & 0.375 & 0.0358 & 0.0338 & 0.0344 & 0.0248 & 0.0242 & 0.0445 & 0.0543 \\
\hline SST & 0.0040 & 0.0031 & 0.0026 & 0.0042 & 0.0068 & 0.0063 & 0.0084 & 0.0084 & 0.0143 & 0.0270 \\
\hline DAH & 0.4185 & 0.4183 & 0.4186 & 0.4188 & 0.4177 & 0.4170 & 0.4161 & 0.4159 & 0.4118 & 0.4115 \\
\hline SAM & 0.4254 & 0.4249 & 0.4257 & 0.4252 & 0.4253 & 0.4258 & 0.4265 & 0.4264 & 0.4244 & 0.4229 \\
\hline \multirow[t]{2}{*}{ S.MELLO } & 0.2493 & 0.2491 & 0.2496 & 0.2494 & 0.2485 & 0.2487 & 0.2480 & 0.2483 & 0.2476 & 0.2466 \\
\hline & \multicolumn{10}{|c|}{ OSHODI - 12GHz } \\
\hline \multicolumn{11}{|l|}{ MEAN } \\
\hline ITU-R & -0.0342 & -0.0361 & -0.0344 & -0.0333 & -0.0321 & -0.0320 & -0.0273 & -0.0263 & -0.0353 & -0.0400 \\
\hline SST & -0.0026 & -0.0028 & -0.0031 & -0.0033 & 0 & 0 & 0 & 0 & -0.0059 & -0.0133 \\
\hline DAH & -0.0237 & -0.0250 & -0.0219 & -0.0200 & -0.0286 & -0.0320 & -0.0364 & -0.0368 & -0.0529 & -0.0533 \\
\hline SAM & -0.0395 & -0.0417 & -0.0375 & -0.0400 & -0.0393 & -0.0360 & -0.0318 & -0.0316 & -0.0412 & -0.0467 \\
\hline S.MELLO & -0.0184 & -0.0194 & -0.0156 & -0.0167 & -0.0214 & -0.0200 & -0.0227 & -0.0211 & -0.0235 & -0.0267 \\
\hline \multicolumn{11}{|l|}{ STD.DEV } \\
\hline ITU-R & 0.2791 & 0.2788 & 0.2791 & 0.2792 & 0.2793 & 0.2793 & 0.2798 & 0.2799 & 0.2790 & 0.2783 \\
\hline SST & 0.0497 & 0.0497 & 0.0497 & 0.0497 & 0.0498 & 0.0498 & 0.0498 & 0.0498 & 0.0494 & 0.0480 \\
\hline $\mathrm{DAH}$ & 0.3489 & 0.3488 & 0.3490 & 0.3492 & 0.3486 & 0.3483 & 0.3478 & 0.3478 & 0.3457 & 0.3456 \\
\hline SAM & 0.3856 & 0.3854 & 0.3858 & 0.3855 & 0.3856 & 0.3859 & 0.3863 & 0.3863 & 0.3854 & 0.3848 \\
\hline S.MELLO & 0.2071 & 0.2070 & 0.2073 & 0.2073 & 0.2068 & 0.2070 & 0.2067 & 0.2069 & 0.2066 & 0.2062 \\
\hline \multicolumn{11}{|l|}{ RMS } \\
\hline ITU-R & 0.2770 & 0.2765 & 0.2769 & 0.2772 & 0.2775 & 0.2775 & 0.2785 & 0.2787 & 0.2767 & 0.2754 \\
\hline SST & 0.0496 & 0.0496 & 0.0496 & 0.0496 & 0.0498 & 0.0498 & 0.0498 & 0.0498 & 0.0491 & 0.0461 \\
\hline DAH & 0.3481 & 0.3479 & 0.3484 & 0.3486 & 0.3474 & 0.3468 & 0.3459 & 0.3458 & 0.3416 & 0.3415 \\
\hline SAM & 0.3836 & 0.3831 & 0.3840 & 0.3835 & 0.3836 & 0.3842 & 0.3850 & 0.3850 & 0.3832 & 0.3819 \\
\hline \multirow[t]{2}{*}{ S.MELLO } & 0.2063 & 0.2061 & 0.2067 & 0.2066 & 0.2057 & 0.2060 & 0.2054 & 0.2058 & 0.2052 & 0.2045 \\
\hline & \multicolumn{10}{|c|}{ IKEJA - 40GHz } \\
\hline \multicolumn{11}{|l|}{ MEAN } \\
\hline ITU-R & -0.0074 & -0.0077 & -0.0071 & -0.0065 & -0.0059 & -0.0094 & -0.0119 & -0.0133 & -0.0118 & -0.0147 \\
\hline SST & -0.0027 & -0.0021 & -0.0014 & -0.0022 & -0.0022 & -0.0023 & -0.0037 & -0.0031 & -0.0059 & -0.0067 \\
\hline
\end{tabular}


Table 2. Contd.

\begin{tabular}{|c|c|c|c|c|c|c|c|c|c|c|}
\hline \multirow{2}{*}{ P/P models } & \multicolumn{10}{|c|}{ Time Percentage $(p \%)$} \\
\hline & 0.001 & 0.002 & 0.003 & 0.005 & 0.01 & 0.02 & 0.03 & 0.1 & 0.5 & 1.0 \\
\hline DAH & -0.0095 & -0.0091 & -0.0093 & -0.0094 & -0.0089 & -0.0125 & -0.0174 & -0.0173 & -0.0200 & -0.0267 \\
\hline SAM & -0.0128 & -0.0112 & -0.0107 & -0.0116 & -0.0133 & -0.0148 & -0.0220 & -0.0204 & -0.0235 & -0.0333 \\
\hline S.MELLO & -0.0068 & -0.0042 & -0.0043 & -0.0036 & -0.0037 & -0.0070 & -0.0083 & -0.0102 & -0.0106 & -0.0120 \\
\hline \multicolumn{11}{|l|}{ STD.DEV } \\
\hline ITU-R & 0.0999 & 0.0998 & 0.0999 & 0.0999 & 0.1000 & 0.0997 & 0.0994 & 0.0993 & 0.0995 & 0.0991 \\
\hline SST & 0.0361 & 0.0361 & 0.0361 & 0.361 & 0.0361 & 0.0361 & 0.0360 & 0.0360 & 0.0357 & 0.0355 \\
\hline DAH & 0.1513 & 0.1513 & 0.1513 & 0.1513 & 0.1513 & 0.1511 & 0.1506 & 0.1506 & 0.1503 & 0.1492 \\
\hline SAM & 0.1867 & 0.1868 & 0.1869 & 0.1868 & 0.1867 & 0.1866 & 0.1859 & 0.1860 & 0.1857 & 0.1842 \\
\hline S.MELLO & 0.0763 & 0.0765 & 0.0765 & 0.0765 & 0.0765 & 0.0763 & 0.0761 & 0.0759 & 0.0758 & 0.0756 \\
\hline \multicolumn{11}{|l|}{ RMS } \\
\hline ITU-R & 0.0996 & 0.0096 & 0.0996 & 0.0997 & 0.0998 & 0.0993 & 0.0987 & 0.0984 & 0.0988 & 0.0980 \\
\hline SST & 0.0360 & 0.0360 & 0.0361 & 0.360 & 0.0360 & 0.0360 & 0.0358 & 0.0359 & 0.0352 & 0.0349 \\
\hline $\mathrm{DAH}$ & 0.1510 & 0.1511 & 0.1510 & 0.1510 & 0.1511 & 0.1506 & 0.1496 & 0.1496 & 0.1489 & 0.1486 \\
\hline SAM & 0.1863 & 0.1865 & 0.1865 & 0.1864 & 0.1862 & 0.1860 & 0.1846 & 0.1849 & 0.1842 & 0.1811 \\
\hline S.MELLO & 0.0760 & 0.0763 & 0.0763 & 0.0764 & 0.0764 & 0.0759 & 0.0757 & 0.0752 & 0.0751 & 0.0747 \\
\hline & \multicolumn{10}{|c|}{ OSHODI - 40GHz } \\
\hline \multicolumn{11}{|l|}{ MEAN } \\
\hline ITU-R & -0.0068 & -0.0070 & -0.0064 & -0.0068 & -0.0052 & -0.0086 & -0.0110 & -0.0122 & -0.0106 & -0.0133 \\
\hline SST & -0.0014 & -0.0014 & -0.0007 & -0.0014 & -0.0015 & -0.0016 & -0.0018 & -0.0020 & 0 & -0.0053 \\
\hline $\mathrm{DAH}$ & -0.0081 & -0.0077 & -0.0079 & -0.0087 & -0.0081 & -0.0117 & -0.0156 & -0.0163 & -0.0188 & -0.0240 \\
\hline SAM & -0.0122 & -0.0105 & -0.0100 & -0.0109 & -0.0126 & -0.0141 & -0.0202 & -0.0194 & -0.0212 & -0.0307 \\
\hline S.MELLO & -0.0054 & -0.0035 & -0.0036 & -0.0029 & -0.0030 & -0.0063 & -0.0073 & -0.0092 & -0.0094 & -0.0107 \\
\hline \multicolumn{11}{|l|}{ STD.DEV } \\
\hline ITU-R & 0.0909 & 0.0909 & 0.0909 & .910 & 0.0910 & 0.0908 & 0.0905 & 0.0903 & 0.0906 & 0.0902 \\
\hline SST & 0.0216 & 0.0216 & 0.0217 & 0.0216 & 0.0216 & 0.0216 & 0.0216 & 0.0216 & 0.0217 & 0.0210 \\
\hline $\mathrm{DAH}$ & 0.1378 & 0.1379 & 0.1378 & 0.1378 & 0.1378 & 0.1376 & 0.1372 & 0.1371 & 0.1368 & 0.1360 \\
\hline SAM & 0.1729 & 0.1730 & 0.1731 & 0.1730 & 0.1729 & 0.1728 & 0.1722 & 0.1723 & 0.1720 & 0.1706 \\
\hline S.MELLO & 0.0669 & 0.0671 & 0.0671 & 0.0671 & 0.0671 & 0.0669 & 0.0668 & 0.0665 & 0.0665 & 0.0663 \\
\hline \multicolumn{11}{|l|}{ RMS } \\
\hline ITU-R & 0.0907 & 0.0906 & 0.0907 & 0.0908 & 0.0909 & 0.0904 & 0.0898 & 0.0895 & 0.0899 & 0.0892 \\
\hline SST & 0.0216 & 0.0216 & 0.0216 & 0.0216 & 0.0216 & 0.0216 & 0.0215 & 0.0215 & 0.0217 & 0.0203 \\
\hline $\mathrm{DAH}$ & 0.1376 & 0.1376 & 0.1376 & 0.1375 & 0.1376 & 0.1371 & 0.1363 & 0.1361 & 0.1355 & 0.1338 \\
\hline SAM & 0.1725 & 0.1727 & 0.1728 & 0.1727 & 0.1724 & 0.1722 & 0.1710 & 0.1712 & 0.1707 & 0.1678 \\
\hline S.MELLO & 0.0667 & 0.0670 & 0.0670 & 0.0670 & 0.0670 & 0.0666 & 0.0664 & 0.0659 & 0.0658 & 0.0654 \\
\hline
\end{tabular}

$\mathrm{P} / \mathrm{P}$ models $=$ Parameter $/$ Prediction Models. 